\title{
Indirect cyclopexy for treatment of a chronic traumatic cyclodialysis cleft with hypotony
}

This article was published in the following Dove Press journal:

Clinical Ophthalmology

22 March 2014

Number of times this article has been viewed

\section{Nisha Chadha \\ Tania Lamba \\ David A Belyea \\ Kunal Y Merchant \\ Department of Ophthalmology, The George Washington University, Washington, DC, USA}

\begin{abstract}
Cyclodialysis cleft is a rare clinical finding and therefore, reports on surgical repair techniques in the literature are limited. Additionally, hypotony can make repair technically challenging. We share a novel, simple surgical approach to management of a case of chronic traumatic cyclodialysis cleft with a successful outcome.
\end{abstract}

Keywords: surgical repair, low intraocular pressure, choroidals, shallow anterior chamber

\section{Introduction}

Cyclodialysis cleft is a rare clinical finding, but one that can have significant ocular complications, including decreased vision, shallowing of the anterior chamber, corneal edema, hypotony, choroidal effusions, maculopathy, vascular tortuosity, and optic disc edema. While it can be caused by surgical manipulation of the eye, it is more frequently a consequence of trauma. ${ }^{1}$ Traumatic injury to the eye results in separation of the ciliary body from the scleral spur, which creates an aberrant outflow pathway for aqueous humor through the suprachoroidal space and often leads to hypotony. Cyclodialysis cleft has been reported to occur in $3.4 \%$ of cases of ocular injury or globe rupture. ${ }^{2}$ Additionally, one large review of 291 cases involving cyclodialysis suggested that hypotony occurs $9 \%$ of the time. ${ }^{3}$ Medical treatment with atropine ophthalmic drops and laser therapy to promote reattachment of the ciliary body to the scleral spur are options for repair of this entity, but larger and more chronic cyclodialyses often require surgical repair. ${ }^{4,5}$ Because of their rarity, reports on surgical repair techniques in the literature are limited. Additionally, hypotony can make surgical repair technically challenging. We share a novel, simple surgical approach to management of a case of chronic traumatic cyclodialysis cleft with a successful outcome.

\section{Case report}

A 70-year-old Caucasian male followed at the Martinsburg Veterans Affair Hospital Ophthalmology Clinic, Martinsburg, West Virginia, USA, since 2002 was found consistently to have intraocular pressure (IOP) asymmetry, with the right eye IOP ranging from $6-15 \mathrm{mmHg}$ and usually having an IOP $04 \mathrm{mmHg}$ lower than the left eye. He was monitored for primary open-angle glaucoma and was on latanoprost eye drops in the left eye for field defects in that eye. In April 2008, his right eye IOP dropped to $04 \mathrm{mmHg}$. On further evaluation, gonioscopy revealed a cyclodialysis cleft from 11-4 o'clock. The patient's history was significant for trauma to the right eye with a piece of wood over 30 years ago, which was thought to be the cause of the cleft.
Correspondence: Tania Lamba Department of Ophthalmology, The George Washington University, 2150 Pennsylvania Avenue, Suite 2A, Washington, DC 20037, USA

Tel +I $20274|28| 4$

Email tania_lamba@yahoo.com 
While the patient had hypotony, he maintained good visual acuity, ranging from $20 / 25$ to $20 / 40$, and was therefore observed for approximately 3 years until December 2011. At this visit, his visual acuity dropped to $20 / 150$ and he clinically developed Descemet's folds with a shallow anterior chamber and an IOP of $02 \mathrm{mmHg}$. On dilated fundus exam, he had a shallow choroidal hemorrhage and effusion in the far nasal periphery. The patient was initially treated medically with atropine and prednisolone acetate $1 \%$ ophthalmic drops for approximately 2 months, without improvement in IOP and with persistence of choroidal hemorrhage and effusion. Vision also remained poor. Given the chronicity and size of this cyclodialysis cleft, surgical repair was planned.

An indirect method of closure was performed and the technique is described below. Postoperatively, the choroidal effusion resolved, but the patient's IOP did not improve. On repeat gonioscopy, it was determined that there were 2 clock hours of remaining cleft. Therefore, the patient was taken for additional surgical repair of the persistent cleft by the same technique, this time with successful closure.

On postoperative day 1 following the second surgery, the patient complained of severe eye pain and nausea, and was found to have an $1 \mathrm{OP}$ of $58 \mathrm{mmHg}$. Elevated intraocular pressure was anticipated with successful closure of cyclodialysis cleft. The patient was treated with topical anti-glaucoma drops and oral acetazolamide, with reduction in the IOP to the mid-teens and resolution of his pain. On exam, there was no distortion of the pupil by sutures and the anterior chamber appeared deep (Figure 1). Repeat gonioscopy also confirmed cleft closure (Figure 2). The patient was subsequently tapered off the oral acetazolamide and topical drops, with stabilization of the pressure in the mid-teens and maintenance of 20/70 visual acuity at 1 year postoperatively. Final visual acuity was limited by subsequent progression of ocular comorbidities in that eye, including cataract and proliferative diabetic retinopathy.

\section{Surgical technique}

A nasal conjunctival peritomy was performed, and dissection down to bare sclera was carried out and continued superotemporally to encompass the region of the cyclodialysis cleft. A 10-0 nylon suture on CS175-6 needle (Ethicon), which is

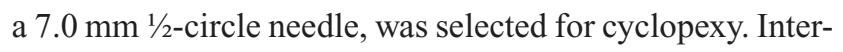
rupted 10-0 nylon sutures were radially passed through the corneal side of the limbus, then through the iris root and ciliary body, and carried out through the sclera on the opposite

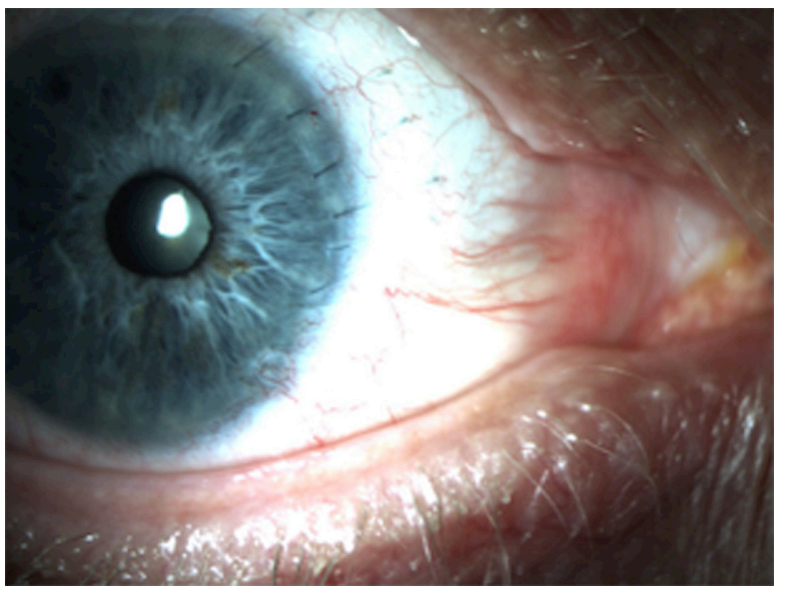

Figure I Anterior segment photograph of eye after cyclodialysis repair. Note: Radial appearance of sutures and round pupil without distortion from sutures.

side of the limbus (Figure 3). To ensure that ciliary body was incorporated into each pass, the sutures were tugged on intraoperatively and the iris root was evaluated for movement with mechanical pull. Additionally, as more sutures were

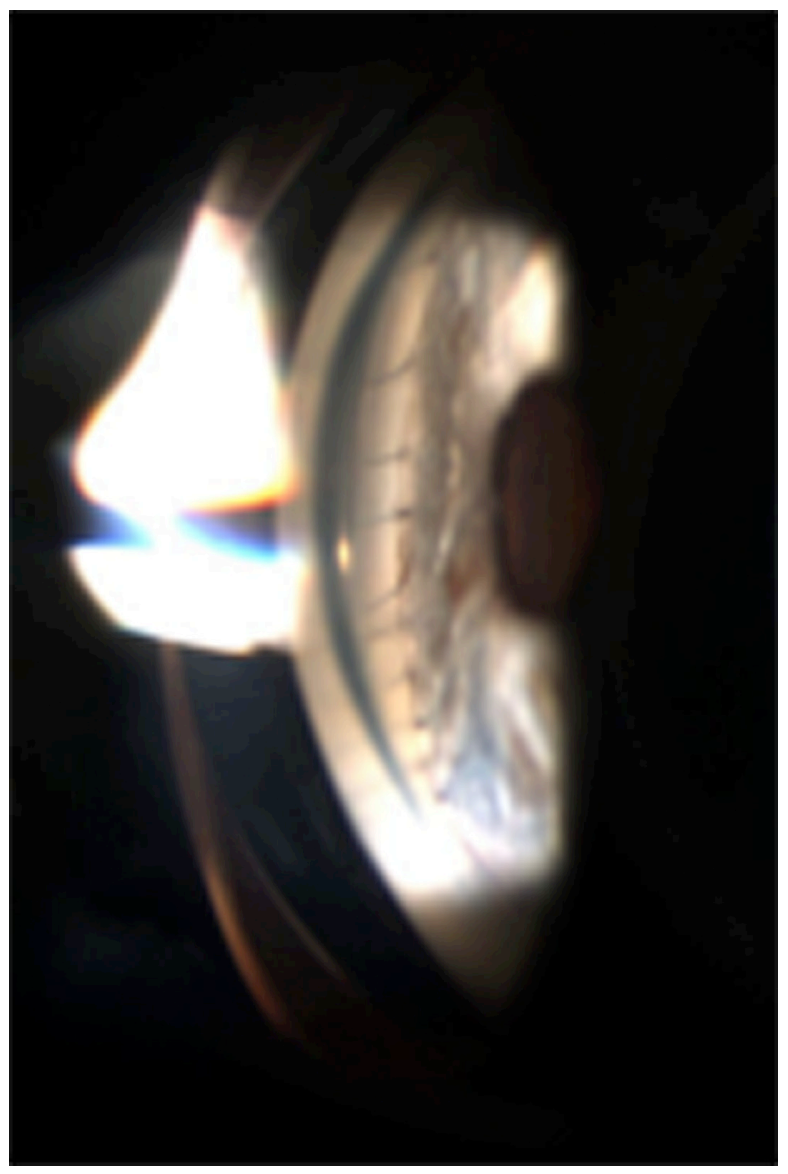

Figure 2 Gonioscopic view of the cyclodialysis cleft after repair.

Note: The sutures are visible crossing the angle and previous cyclodialysis cleft is no longer present. 
placed, the eye appeared to become more firm. The sutures were placed approximately $1 \mathrm{~mm}$ apart. We found the needle type to have a curvature and size that was very helpful for the angle and length of the pass required.

\section{Discussion}

Multiple approaches to cleft closure have been described in the literature, including medical management, laser photocoagulation, cryotherapy, trans-scleral diathermy, gas tamponade, and anterior scleral buckle, along with various surgical repair techniques. ${ }^{6}$ While different surgical approaches have been described, many are technically challenging, particularly in the hypotonous eye. In this case report, we discuss the repair of a chronic traumatic cyclodialysis with indirect surgical cyclopexy, which we found to be technically easier and less invasive than other reported techniques, but equally successful. Compared to the direct cyclopexy described in a review by Ioannidis and Barton, ${ }^{6}$ our indirect technique eliminated the need for direct visualization of the ciliary body, thereby reducing technical difficulty along with bleeding and wound dehiscence risk. Additionally, compared to cyclopexy described by McCannel, ${ }^{7}$ our approach eliminated the additional need for clear corneal stab incision with retrieval of suture, which can also be difficult in a soft, hypotonous eye and may prolong surgical time.

While our technique was successful, it required two operations to achieve successful cleft closure with improvement in IOP. Our first attempt failed, likely due to the spacing of our sutures in one particular quadrant, which we determined were too far apart. Additionally, we used a needle with less curvature and length initially. We found that spacing the sutures approximately $1 \mathrm{~mm}$ apart achieved good apposition of ciliary body to scleral spur and, ultimately, closure of the cleft with restoration of physiologic IOP. The length and curvature of the CS175-6 (Ethicon, Cincinnati, Ohio, USA) needle also assisted with passage of each suture through the targeted tissues. The patient's postoperative IOP spike after the second surgery was suggestive of successful closure of the cleft. ${ }^{1}$ Additionally, successful closure was later confirmed by gonioscopy.

Another challenge to our case was the chronicity of the injury which was sustained 30 years prior to presentation as per the patient's self-reported history. There was concern that, even with successful anatomic closure, IOP and visual function may not be restored due to chronic ischemic changes to the ciliary body. However, our repair achieved both anatomic and functional success, suggesting that even chronic
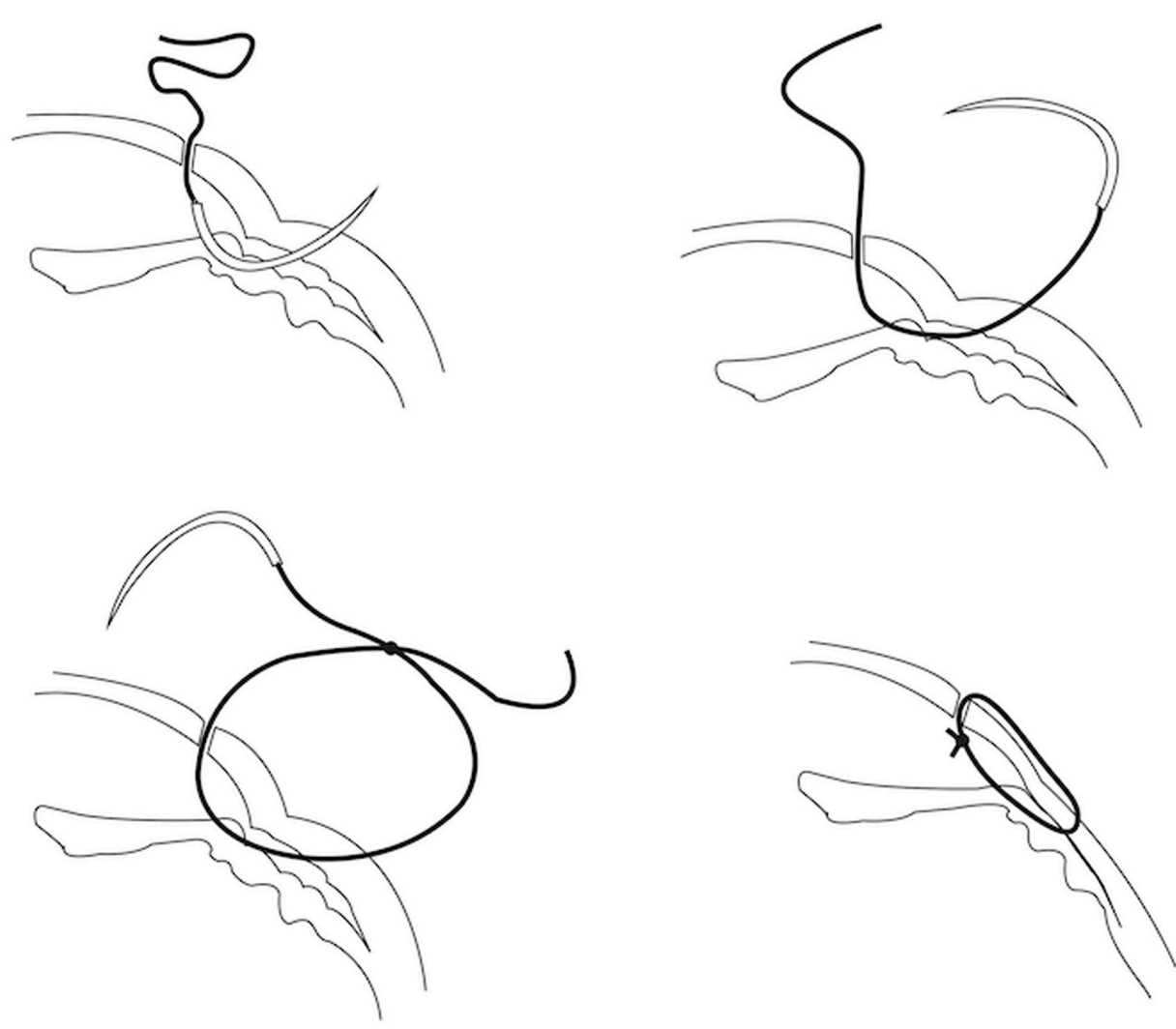

Figure 3 Schematic drawing of indirect cyclopexy technique. Note: Illustration by Michael Leong. 
cyclodialysis clefts can be effectively repaired. Delgado et al reported a similar finding in a case of hypotony maculopathy secondary to cyclodialysis that was resolved with cleft closure 7 years later. ${ }^{8}$

Cyclodialysis is a vision-threatening ocular injury that can often be difficult to treat medically. Surgical repair is often necessary but can be technically difficult and challenging, particularly because of how rarely it is encountered in clinical practice. We present a simple, less-invasive approach to surgical cleft closure that was successful anatomically and functionally. Additionally, we demonstrate clinical success with cleft closure in an eye with chronic hypotony.

\section{Disclosure}

The authors report no conflicts of interest in this work.

\section{References}

1. Küchle M, Naumann GO. Direct cyclopexy for traumatic cyclodialysis with persisting hypotony: report in 29 consecutive patients. Ophthalmology. 1995;102:322-333.
2. Viestenz A, Küchle M. [Retrospective analysis of 417 cases of contusion and rupture of the globe with frequent avoidable causes of trauma: the Erlangen Ocular Contusion-Registry (EOCR) 1985-1995]. Klin Monbl Augenheilkd. 2001;218(10):662-669. German.

3. Viikari K, Tuovinen E. On hypotony following cyclodialysis surgery. Acta Ophthalmol (Copenh). 1957;35:543-549.

4. Aminlari A, Callahan CE. Medical, laser, and surgical management of inadvertent cyclodialysis cleft with hypotony. Arch Ophthalmol. 2004; 122(3):399-404.

5. Joondeph HC. Management of postoperative and post-traumatic cyclodialysis clefts with argon laser photocoagulation. Ophthalmic Surg. 1980;11(3):186-188.

6. Ioannidis AS, Barton K. Cyclodialysis cleft: causes and repair. Curr Opin Ophthalmol. 2010;21(2):150-154.

7. McCannel MA. A retrievable suture idea of anterior uveal problems. Ophthalmic Surg. 1976;7:98-103.

8. Delgado MF, Daniels S, Pascal S, Dickens CJ. Hypotony maculopathy: improvement of visual acuity after 7 years. Am J Ophthalmol. 2001; 132(6):931-933.
Clinical Ophthalmology

\section{Publish your work in this journal}

Clinical Ophthalmology is an international, peer-reviewed journal covering all subspecialties within ophthalmology. Key topics include: Optometry; Visual science; Pharmacology and drug therapy in eye diseases; Basic Sciences; Primary and Secondary eye care; Patient Safety and Quality of Care Improvements. This journal is indexed on

\section{Dovepress}

PubMed Central and CAS, and is the official journal of The Society of Clinical Ophthalmology (SCO). The manuscript management system is completely online and includes a very quick and fair peer-review system, which is all easy to use. Visit http://www.dovepress.com/ testimonials.php to read real quotes from published authors. 